\title{
Peptidoglycan and Arabinogalactan of Mycobacterium leprae
}

\author{
By PHILIP DRAPER, ${ }^{*}$ OTTO KANDLER ${ }^{2}$ AND ANDRÉ DARBRE 3 \\ ${ }^{1}$ National Institute for Medical Research, Mill Hill, London NW7 IAA, UK \\ 2 Department of Biochemistry, King's College London, Strand, London WC2R 2LS, UK \\ ${ }^{3}$ Botanisches Institut der Universität München, 8000 München, Menzinger Strasse 67, \\ Federal Republic of Germany
}

(Received 15 September 1986; revised 27 October 1986)

\begin{abstract}
The arabinogalactan and peptidoglycan of armadillo-grown Mycobacterium leprae were examined. Within the limits defined by the small amount of material available, the resemblance of these polymers to those of other mycobacteria was confirmed. The polymers were linked by a highly acid-labile bond and the arabinogalactan was itself acid-labile; free arabinose and a variety of oligosaccharides containing both arabinose and galactose, as well as polysaccharide and peptidoglycan, were released by dilute acid. The resonances from anomeric protons in the proton NMR spectrum of the arabinogalactan were similar to those from the arabinogalactan of $M$. tuberculosis. The composition and structure of the peptidoglycan resembled those of other mycobacteria. The only major difference was the specific replacement of $\mathrm{L}$-alanine by glycine in the peptide of the peptidoglycan.
\end{abstract}

\section{INTRODUCTION}

Mycobacterial surfaces present to the environment a remarkable variety of substances, especially complex lipids, but these are mostly not attached covalently to the bacterial wall (Minnikin, 1982). The fundamental wall structure that remains when components extractable without breaking chemical bonds have been removed (Lederer, 1971, 1975) is apparently very similar in most species. It consists of a peptidoglycan of the common chemotype Al $\gamma$ (Schleifer $\&$ Kandler, 1972), unusual only in that the muramic acid is acylated with glycollic acid rather than acetic acid. Attached to this, entirely or mostly by phosphodiester bonds to carbon 6 of muramic acid, is a branched arabinogalactan which in turn is esterified at its outer ends with characteristic long-chain fatty acids, mycolic acids. Variation in the mycolic acids seems to be the only major difference amongst walls of most mycobacterial species (Minnikin et al., 1985).

One of us reported (Draper, 1976) that Mycobacterium leprae differed in another way: the Lalanine of the usual mycobacterial peptidoglycan was replaced by glycine. Another group (David \& Rastogi, 1983) failed to confirm this observation but a general shortage of cells of $M$. leprae has made a thorough study difficult. The wall of $M$. leprae is of some interest, both as a possible taxonomic marker and as offering a partial explanation for the survival of this pathogen inside phagocytic cells. We report here further investigations on the walls of this organism.

\section{METHODS}

Preparation of walls. Crude walls of $M$. leprae were obtained as a by-product of the production of cell-free extracts for use as skin-test reagents or for biochemical study. The bacteria were purified from tissues of experimentally infected nine-banded armadillos by two methods devised by one of us for the IMMLEP Steering Committee of the UNDP/World Bank/WHO Special Programme for Research and Training in Tropical Diseases (method IV of Shepard et al., 1980; World Health Organization, 1980). Purified bacteria, approx. $1 \mathrm{mg} \mathrm{ml}^{-1}$ in

Abbreviation: DAP, diaminopimelic acid. 
water or $0 \cdot 15 \mathrm{M}-\mathrm{NaCl}$, were sonicated at $4{ }^{\circ} \mathrm{C}$ for $20 \mathrm{~min}$ with a Dawe Soniprobe operated at $80 \mathrm{~W}$. The sonicates were centrifuged at $105000 \mathrm{~g}$ to pellet the crude walls, which were collected and stored at $-20^{\circ} \mathrm{C}$ until sufficient material was available for further processing.

Crude walls were thawed and sonicated $(80 \mathrm{~W})$ in a small volume of residual liquid $(<0.15 \mathrm{M}-\mathrm{NaCl})$ for $10 \mathrm{~min}$ at $4{ }^{\circ} \mathrm{C}$ to break up clumps. The material was then suspended in $40 \mathrm{ml} \mathrm{0.15} \mathrm{M}$-HEPES buffer, $\mathrm{pH} \mathrm{7.2,} \mathrm{containing}$ $1 \mathrm{mM}-\mathrm{MgSO}_{4}, 0.1 \%(\mathrm{w} / \mathrm{v})$ Tween 80 and $0.05 \%$ sodium azide, and digested with deoxyribonuclease type I (Worthington) plus ribonuclease (Koch-Light; each approx. $100 \mu \mathrm{g} \mathrm{ml}^{-1}$ ) at room temperature for $16 \mathrm{~h}$ followed by trypsin plus chymotrypsin (Armour; $100 \mu \mathrm{g} \mathrm{ml}^{-1}$ ) at room temperature for $24 \mathrm{~h}$. Sodium dodecyl sulphate was added to a final concentration of $1 \%(\mathrm{w} / \mathrm{v})$ and the suspensions were kept for a further $24 \mathrm{~h}$ at room temperature. The walls were collected by centrifuging at $12000 \mathrm{~g}$ for $30 \mathrm{~min}$, washed twice with $0 \cdot 1 \%(\mathrm{w} / \mathrm{v})$ Tween 80 buffered to $\mathrm{pH}$ 6.8 with $1 \mathrm{mM}$-MES (buffered Tween), once with $1 \mathrm{M}-\mathrm{NaCl}$ and finally with buffered Tween. The walls were separated from residual unbroken bacteria and powdered titanium from the sonicator probe in linear gradients of 15 to $50 \%(w / w)$ sucrose in buffered Tween centrifuged at $34800 \mathrm{~g}$ for $4 \mathrm{~h}$, then washed with water and freezedried.

One batch of walls used to study the isomers of diaminopimelic acid present was prepared from bacteria broken in a Mickle cell disintegrator for $10 \mathrm{~min}$, using $72.9 \mathrm{mg} \mathrm{M}$. leprae suspended in $3 \mathrm{ml} 0.9 \%(\mathrm{w} / \mathrm{v}) \mathrm{NaCl} \mathrm{plus} 3 \mathrm{~g}$ Ballotini beads. After the walls had been washed free from beads they were processed as above.

Non-covalently-bound lipids were removed by extraction with chloroform/methanol $(2: 1, v / v)$ for $4 \mathrm{~d}$ at room temperature; walls were collected by centrifuging after dilution of the solvent to chloroform/methanol $(1: 1, \mathrm{v} / \mathrm{v})$.

Preparation of polysaccharide and peptidoglycan by a two-stage method. Methods were modified from those of Draper (1971) and Davidson et al. (1982). A sample of purified walls (15 mg) was suspended in $15 \mathrm{ml} 0.5 \%$ (w/v) $\mathrm{KOH}$ in methanol and kept at $37^{\circ} \mathrm{C}$ for $4 \mathrm{~d}$, then washed with methanol and dried. Freed mycolic acid methyl esters were extracted with diethyl ether. The lipid-free walls were dried, suspended in $10 \mathrm{ml}$ of $0.05 \mathrm{M}-\mathrm{H}_{2} \mathrm{SO}_{4}$ and kept at $37^{\circ} \mathrm{C}$ for $5 \mathrm{~d}$. The residue (peptidoglycan) was collected, washed twice with water and freeze-dried. The supernate, containing released and partially degraded polysaccharide, was neutralized with $\mathrm{BaCO}_{3}$. $\mathrm{BaSO}_{4}$ and $\mathrm{BaCO}_{3}$ were removed by filtration through Whatman no. 50 paper and the clear filtrate was dried at $40^{\circ} \mathrm{C}$ in a rotary evaporator.

Preparation of polysaccharide and peptidoglycan by a single-stage method. This method was a simplified version of that used by Misaki et al. (1974). Purified walls $(33 \mathrm{mg}$ ) were suspended in $10 \mathrm{ml} 0.5 \mathrm{M}-\mathrm{NaOH}$, sparged with nitrogen to remove dissolved oxygen, sealed and heated at $70^{\circ} \mathrm{C}$ for $8 \mathrm{~h}$ with occasional shaking. After cooling, the alkali was neutralized with $0.29 \mathrm{ml}$ glacial acetic acid. Insoluble material was collected by centrifuging $(12000 \mathrm{~g}$, $30 \mathrm{~min}$ ), washed with water, freeze-dried, extracted with diethyl ether to remove residual mycolic acid and finally dried.

The neutral supernate was extracted twice with diethyl ether, dried, redissolved in $6 \mathrm{ml}$ water and treated with $36 \mathrm{ml}$ ethanol and 1 drop $1 \mathrm{M}-\mathrm{CaCl}_{2}$. After $5 \mathrm{~d}$ at $4{ }^{\circ} \mathrm{C}$ precipitated material was collected, dissolved in $5 \mathrm{ml}$ water and precipitated with $30 \mathrm{ml}$ ethanol. After $1 \mathrm{~d}$ at $4{ }^{\circ} \mathrm{C}$ the precipitated material was collected, dissolved in $3 \mathrm{ml}$ water and centrifuged at $12000 \mathrm{~g}$ for $1 \mathrm{~h}$. (The sediment, presumably mostly peptidoglycan solubilized by the alkali, was not further studied.) The supernate, plus washings, was precipitated at $4{ }^{\circ} \mathrm{C}$ with 5 vols ethanol and a trace of $\mathrm{CaCl}_{2}$. The precipitated polysaccharide was redissolved in a known volume of water for further analysis.

NMR spectrometry. Polysaccharide prepared by the one-step method was dissolved in $\mathrm{D}_{2} \mathrm{O}$, freeze-dried to displace $\mathrm{H}_{2} \mathrm{O}$ and redissolved in $\mathrm{D}_{2} \mathrm{O}$. It was examined in a Bruker AM500 NMR spectrometer operating at $500 \mathrm{MHz}$ with a spectral width of $4 \mathrm{kHz}$.

Determination of sequence and cross-linkage of peptidoglycan. The amino acid sequence of the peptidoglycan was elucidated by paper chromatographic analysis of partial acid hydrolysates $\left(4 \mathrm{M}-\mathrm{HCl}, 100^{\circ} \mathrm{C}, 20 \mathrm{~min}\right)$, according to the methods of Schleifer \& Kandler (1972). Peptides were identified on the basis of their positions on twodimensional chromatograms, their colour after spraying with ninhydrin and the identity of the amino acids released after complete hydrolysis. Dinitrophenylation and hydrazinolysis were performed as described by Hammes et al. (1973).

Determination of optical isomers of alanine and glutamic acid as $N$-trifluoroacetyl-L-prolyl amino acid methyl esters. A sample of peptidoglycan $(2.6 \mathrm{mg})$ was hydrolysed with $4 \mathrm{M}-\mathrm{HCl}$ at $105^{\circ} \mathrm{C}$ for $16 \mathrm{~h}$, then dried in vacuo over $\mathrm{NaOH}$. The material was esterified with $4 \mathrm{M}-\mathrm{HCl}$ in methanol at $70^{\circ} \mathrm{C}$ for $30 \mathrm{~min}$ and evaporated to dryness (Darbre \& Islam, 1968). The residue was treated with an excess $(0.2 \mathrm{ml})$ of $N$-trifluoroacetyl-L-prolyl chloride at room temperature for $1 \mathrm{~h}$ (see Halpern, 1977), cooled to below $10^{\circ} \mathrm{C}$ and partially neutralized with triethylamine $(50 \mu \mathrm{l})$. A sample $(1 \mu \mathrm{l})$ was injected directly onto a GLC column operated isothermally at $179^{\circ} \mathrm{C}$ to study glutamic acid and at $152^{\circ} \mathrm{C}$ to study alanine. Relative amounts of the optical isomers were determined from areas of peaks and comparison with standards. GLC was carried out with a Pye series 104, model 24, gas chromatograph equipped with dual flame-ionization detectors. Glass columns $(3.25 \mathrm{~m} \times 2.5 \mathrm{~mm}$ i.d.) were packed with HP Chromosorb W, 80-100 mesh, coated with $2 \cdot 5 \%$ (w/w) of mixed stationary phase (Darbre \& Islam, 1968), consisting of XE-60, QF-1 and MS 200 (46:27:27, by wt).

Determination of optical isomer of diaminopimelic acid (DAP). Commercial DAP (Sigma) was separated into 


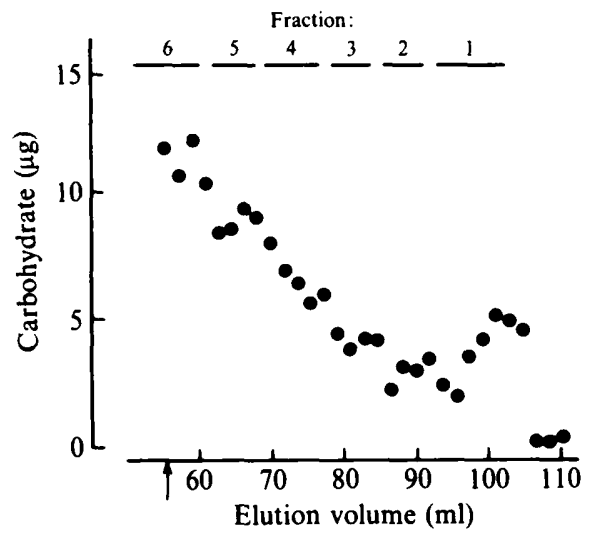

Fig. 1. Fractionation of oligosaccharides from walls of $M$. leprae. Carbohydrate $(3.01 \mathrm{mg})$ removed from walls of $M$. leprae by the two-stage method was applied to a Biogel P-2 column $(25 \times 235 \mathrm{~mm})$ and eluted with water at a flow rate of $22 \mathrm{ml} \mathrm{h}^{-1}$. Fractions $(2 \mathrm{ml})$ were sampled $(0.1 \mathrm{ml})$ and assayed for carbohydrate by the method of Dubois et al. (1956), and were then pooled as indicated for further study. The arrow indicates the position of the column void volume.

fractions containing LL-DAP and DD- plus meso-DAP on cellulose thin-layer plates (Merck) using the solvent of Hoare \& Work (1957). Material was released from scraped-off areas with $0.05 \mathrm{M}-\mathrm{HCl}$ and the extracts were dried in vacuo over $\mathrm{NaOH}$ pellets with $\mathrm{H}_{2} \mathrm{SO}_{4}$ also present in the desiccator to remove traces of pyridine from the chromatographic solvent.

Di-(2,4-dinitrophenyl) derivatives of racemic DAP, chromatographic fractions and DAP in hydrolysates of peptidoglycan of $M$. leprae were prepared by the method of Bricas et al. (1967), involving addition of 1 vol. $0.01 \mathrm{M}$ ethanolic 2,4-dinitrofluorobenzene to 10 vols of a solution of amino acids in $1 \%(w / v)$ sodium borate. Derivatives were extracted with diethyl ether from the acidified $(2 \mathrm{M}-\mathrm{HCl})$ solution and analysed by TLC on silica-gel 60 plates (Merck) using solvent III of Bricas et al. [benzyl alcohol/chloroform/methanol/water/15 M-ammonia $(30: 30: 30: 6: 2$, by vol. $)]$.

Separation of oligosaccharides. Polysaccharide $\left(3 \mathrm{mg}\right.$ ) prepared by the two-stage method was separated by $\boldsymbol{M}_{\mathrm{r}}$ fractions using a Biogel P-2 (Bio-Rad) column, $25 \times 235 \mathrm{~mm}$, run at $22 \mathrm{ml} \mathrm{h}^{-1}$ with water as the eluent (Fig. 1). The void volume of the column was measured with Blue Dextran (Sigma) and approximate $M_{\mathrm{r}}$ values of eluted fractions were calculated using a standard curve relating elution volumes to $M_{r}$ values of galactose, sucrose, raffinose and stachyose in a separate column of similar dimensions.

Analytical methods. Samples for amino acid analysis (usually about $1 \mathrm{mg}$ ) were hydrolysed in sealed tubes with $4 \mathrm{M}-\mathrm{HCl}$ at $105^{\circ} \mathrm{C}$ for $16 \mathrm{~h}$. Lipid or charred material was removed by filtering through Whatman no. 50 filter paper and the hydrolysates were evaporated in vacuo over $\mathrm{NaOH}$. The samples were examined in a Beckman automatic amino acid analyser; amounts of amino-compounds were calculated from measured areas of peaks using regularly checked colour factors.

Glycollic acid was measured by the method of Uchida \& Aida (1977), with elution volumes adjusted to allow small columns of ion-exchange resin in Pasteur pipettes to be used.

Carbohydrates were examined by TLC on cellulose thin-layer plates using $n$-butanol/acetic acid/water $(4: 1: 1$, by vol.) as solvent and aniline phthalate to detect sugars.

Composition of carbohydrate samples was determined by GLC of trimethylsilyl derivatives of methyl glycosides.

Neutral sugars were estimated by the method of Dubois et al. (1956), using galactose as a standard but measuring extinctions at $480 \mathrm{~nm}$. Polysaccharide samples were not normally hydrolysed before estimation.

Reducing sugars were estimated by the method of Park \& Johnson (1949).

\section{RESULTS}

\section{Composition of peptidoglycan}

Results of automatic amino acid analysis of peptidoglycan prepared by the single-stage method (duplicate samples) confirmed those reported earlier by one of us (Draper, 1976). Relative to DAP $=1 \mathrm{~mol}$ there were $0.88 \mathrm{~mol}$ alanine, $1.13 \mathrm{~mol}$ glycine and $0.98 \mathrm{~mol}$ glutamic acid. Traces of 'non-wall' amino acids were present, but amounts were too small for accurate quantification: less than $0.09 \mathrm{~mol}$ (relative to DAP) of the most abundant, aspartic acid, was 
detected. The structure of the 'standard' mycobacterial peptidoglycan (Lederer, 1975) contains no glycine and twice as much alanine at DAP, so the replacement of alanine by glycine in the peptidoglycan of $M$. leprae was evident from our analyses. A small peak corresponding to muramic acid phosphate was present in the chromatograms.

The DAP in the peptidoglycan of $M$. leprae was apparently all the meso-isomer, as judged by TLC on cellulose plates. The free amino acid from the walls had a mobility different from LLDAP and similar to meso- and DD-DAP (which are not separated). The di-(2,4-dinitrophenyl)DAP from $M$. leprae had a mobility on silica-gel plates different from that of DD- and LL-DAP (which are not separated) and similar to that of di-(2,4-dinitrophenyl)-meso-DAP.

Peptidoglycan prepared by the single-stage method contained $1.3 \mathrm{~mol}$ glycollic acid relative to DAP $=1 \mathrm{~mol}$; peptidoglycan prepared by the two-stage method contained a similar amount. Molar ratios of muramic acid were less than the theoretical unity $(0.57)$ relative to DAP, but this is usual in analyses of peptidoglycan, partly because of instability of muramic acid to strong acid. Multiplication by the factor (1.47) determined by Kotani et al. (1975) to correct for losses in hydrolysis gives a molar ratio of 0.84 . Further muramic acid was present as unhydrolysed muramic acid 6-phosphate, but this could not be quantified. It may be inferred that the whole of the muramic acid in the peptidoglycan is present as the $N$-glycollyl derivative.

D- and L-alanine and D- and L-glutamic acid were clearly resolved by GLC of their $N$ trifluoroacetyl methyl esters; both were present in the peptidoglycan predominantly as Disomers $(90 \% \mathrm{D}$-glutamic acid, $87 \% \mathrm{D}$-alanine). Given that traces of 'non-wall' amino acids were present even in purified peptidoglycan, as demonstrated by amino acid analyses, it seems probable that the small amounts of L-alanine and L-glutamic acid were derived from protein contaminants. The glutamic acid in the peptidoglycan was (as usual) the D-isomer and most or all of the L-alanine in the peptidoglycan had been replaced by glycine.

\section{Sequence and cross-linkage of peptidoglycan}

Three peptides, Gly-D-Glu, muramic acid-Gly and meso-DAP-D-Ala, were identified in the partial acid hydrolysates. Gly-D-Glu showed a yellow colour, typical of $N$-terminal glycine, with ninhydrin. The other peptides yielded muramic acid plus glycine, and meso-DAP plus alanine, respectively, after complete hydrolysis. Mono-(2,4-dinitrophenyl)-DAP was the only dinitrophenyl derivative detected in hydrolysates of dinitrophenylated walls, and amounted to about $25 \%$ of the total DAP present. This indicates a degree of cross-linkage of about $75 \%$, a typical value for Gram-positive bacteria. Hydrazinolysis yielded about $10 \%$ of free DAP but no significant amount of alanine, indicating that $\mathrm{D}$-alanine not involved in cross-linkage had been removed by bacterial carboxypeptidase.

\section{Properties of wall polysaccharide}

Duplicate samples of polysaccharide prepared by the single-stage method contained arabinose and galactose in a molar ratio of 3.9 to 1 . Recovery of identifiable carbohydrate was $80 \%$ of the dry weight of the samples. Traces of glucose and mannose were present; amounts were too small for accurate quantification but were about $1 \%$ and $6 \%$, respectively, of the amount of galactose.

A sample of this polysaccharide was compared with a sample of arabinogalactan from $M$. tuberculosis, prepared by alkali extraction of whole cells followed by ethanol fractionation according to the method of Misaki \& Yukawa (1966), by proton NMR spectroscopy in $\mathrm{D}_{2} \mathrm{O}$. The spectra obtained were, as expected, complex, and the resolution of resonances with the very small sample from $M$. leprae was much poorer than that with the more abundant polysaccharide from $M$. tuberculosis. However, a comparison of peaks in the region where resonances from anomeric protons were expected (chemical shifts of 5 to $5 \cdot 3$ p.p.m.) indicated a close resemblance between the two polysaccharides (Fig. 2 and Table 1).

'Polysaccharide' prepared by the two-stage method contained considerable amounts of material having the same mobility on cellulose TLC plates as arabinose, as well as material of lower mobility, not resolved into distinct spots, but apparently oligosaccharide in nature. Individual fractions eluted from the Biogel P-2 column were collected into six pooled fractions 


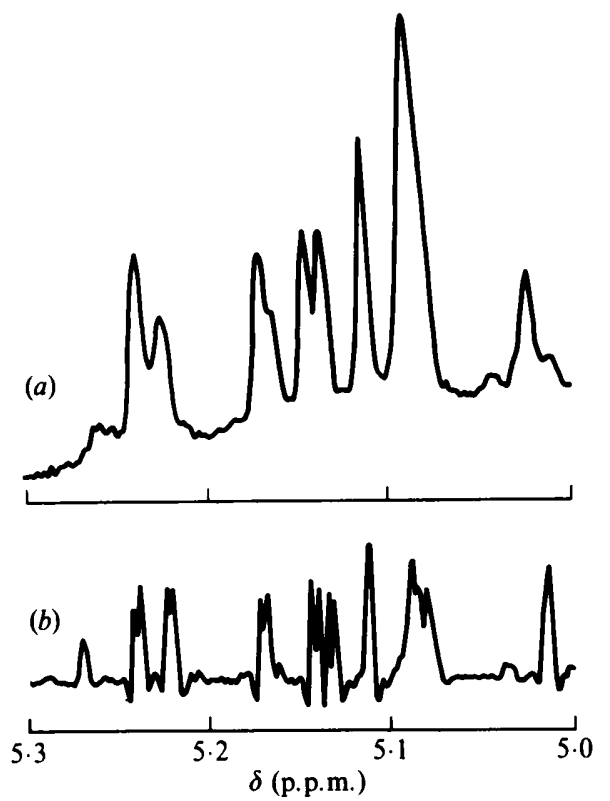

Fig. 2. Proton NMR of mycobacterial wall polysaccharides, showing resonances in the region of sugar anomeric protons. Samples of wall polysaccharide from $M$. leprae $(a)$ and arabinogalactan from $M$. tuberculosis (b) were dissolved in $\mathrm{D}_{2} \mathrm{O}$ and studied in a Bruker AM500 instrument at $500 \mathrm{MHz}$. Note that the spectra were originally recorded on different linear scales, and also that the resolution of the spectrum of the small $M$. leprae polysaccharide sample is much poorer than that of the arabinogalactan from $M$. tuberculosis.

Table 1. Chemical shifts of anomeric protons in wall polysaccharide of $M$. leprae

Proton NMR spectra were obtained as described in Fig. 2 and shifts were measured from the spectra shown.

(a)

$\begin{array}{llllllll}5.239 & 5.225 & 5.168 & 5.144 & 5.134 & 5.11 & 5.083 & 5.019 \\ & & 5 \cdot 162^{*} & & & & 5.076^{*} & \\ 5.242 \ddagger & 5.223 \ddagger & 5.172 \ddagger & 5.144 \ddagger & 5.134 \ddagger & 5.112 & 5.088 \S & 5.013 \\ 5.238 & 5.22 & 5.168 & 5.139 & 5.131 & & 5.085^{*} & \\ & & & & & & 5.08 & \end{array}$

* Shoulder. † Minor resonance - ?contaminant. ‡ Double peak. § Complex peak.

(Fig. 1), which were assayed for total and reducing carbohydrate and analysed for sugar composition by GLC (Table 2). The six pooled fractions accounted for $93 \%$ of the material applied to the column.

It was clear that even the very weak acid used in this hydrolysis caused extensive degradation of the wall polysaccharide. Of the total arabinose in the sample, $10 \%$ was present as the free sugar. Little free galactose was produced but a substantial proportion occurred in oligosaccharides. The overall arabinose : galactose ratio was $3 \cdot 5: 1$, somewhat lower than for polysaccharide obtained by the single-stage method.

\section{DISCUSSION}

Apart from some continuing debate about whether the whole of the arabinogalactan is attached by phosphodiester links to muramic acid or is partly joined to the peptidoglycan by a glycosidic bond (Kanetsuna \& San Blas, 1970; for more recent data on the related Nocardia rubra see Fujioka et al., 1985), the structure of the mycobacterial wall as reviewed by Lederer (1971, 
Table 2. Analysis of oligosaccharide fractions from walls of $M$. leprae

Carbohydrate removed from $M$. leprae walls prepared by the two-stage method $(3.01 \mathrm{mg})$ was fractionated on a Biogel P-2 column as described in Fig. 1. Fractions were assayed as described in Methods.

$\begin{array}{ccccc}\begin{array}{c}\text { Fraction } \\ \text { no. }\end{array} & \begin{array}{c}\text { Approx. } \\ M_{\mathrm{r}}\end{array} & \begin{array}{c}\text { Molar ratio } \\ \text { Ara : Gal }\end{array} & \begin{array}{c}\text { Molar ratio } \\ \text { total : reducing }\end{array} & \begin{array}{c}\text { Amount } \\ (\mathrm{mg})\end{array} \\ 1 & 170 & 45 & 1.5 & 0.31 \\ 2 & 320 & 1 \cdot 6 & 2.8 & 0.15 \\ 3 & 530 & 1 \cdot 6 & 3 \cdot 7 & 0.17 \\ 4 & 800 & 2 \cdot 4 & 4.0 & 0.46 \\ 5 & 1380 & 3 \cdot 3 & 7.3 & 0.58 \\ 6 & >1800 & 4 \cdot 2 & 11.6 & 1 \cdot 13\end{array}$

1975) has not been seriously questioned. The structure of the wall of $M$. leprae conforms to the general structure in most respects. Its mycolic acids have been the subject of several studies (see Minnikin et al., 1985); for the present purpose it matters only that they may be removed by the same methods that work for other mycobacteria - aqueous or methanolic alkali - which implies an ester bond. Dilute methanolic alkali does not remove the polysaccharide from the peptidoglycan.

Insufficient polysaccharide has so far been available from $M$. leprae to allow sequencing but some resemblances to the polysaccharide of other mycobacteria may be deduced. The ratio of arabinose to galactose $(3.9: 1)$ is somewhat higher than that of other mycobacterial arabinogalactans $(2 \cdot 3: 1$ to $2 \cdot 8: 1$; Misaki et al., 1974). Purified wall polysaccharides of some corynebacteria (related to mycobacteria) contain other sugars in major amounts but the polysaccharide from Mycobacterium smegmatis is purely an arabinogalactan (Abou-Zeid et al., 1982). The amounts of mannose and glucose detected by us in the polysaccharide of $M$. leprae are sufficiently small to be dismissed as contamination by soluble arabinomannan and glycogen, respectively.

The extreme sensitivity of the polysaccharide to acid is shared by arabinogalactan of $M$. microti (Davidson, 1976; P. Draper, unpublished observations) and the monosaccharide released is almost entirely arabinose, which is known to be the terminal sugar in other mycobacteria. The acid sensitivity is consistent with the arabinose being in the furanose form, as reported for other mycobacterial arabinogalactans (Misaki et al., 1974). All the oligosaccharides released from the polysaccharide of $M$. leprae contained both galactose and arabinose, which is consistent with the known complex structure of the mycobacterial arabinogalactan. Finally, the resemblance between the chemical shifts of anomeric protons in the polysaccharide from $M$. leprae and an authentic sample of arabinogalactan from $\boldsymbol{M}$. tuberculosis is consistent with these two arabinogalactans having similar structures.

The peptidoglycan of $M$. leprae is also conventional in most respects. It contains glucosamine and muramic acid in approximately equimolar amounts (Draper, 1976; David \& Rastogi, 1983). Sufficient glycollyl residues are present to allow all the muramic acid to be glycollylated. Muramic acid phosphate is apparently present in acid hydrolysates, and this, together with the ease of removal of the polysaccharide with dilute acid, suggests that most of the polysaccharide is attached by conventional phosphodiester links.

The sole difference seems to be in the cross-linking peptide. The present results confirm the original claim by Draper (1976) that alanine is partly replaced by glycine. Further, it is clear that the replacement is site-specific and that the missing alanine is the L-isomer attached to the muramic acid.

One aim of the analysis of the wall of $M$. leprae was to clarify its taxonomic status: whether it is a true mycobacterium and, if so, what other mycobacteria it most resembles. The composition of the peptide cross-links presents an anomaly. The combination of glycine (replacing L-alanine) with meso-DAP in a peptidoglycan has been described in an antibiotic-producing bacterium, Micromonospora olivasterospora (Nara et al., 1977; Kawamoto et al., 1981). The data for 
sequence and cross-linking of the peptidoglycan found by us are consistent with $M$. leprae having the same peptidoglycan structure as Micromonospora olivasterospora. The structure has been described in no other mycobacterium and would be a useful taxonomic marker for $\boldsymbol{M}$. leprae if it did not require such a large amount of material for detection. Other members of the family Actinoplanaceae also have glycine and meso-DAP in the peptidoglycan (Szaniszlo \& Gooder, 1967; Stackebrandt \& Schleifer, 1984).

DNA-hybridization experiments (Athwal et al., 1984) appear to show that $M$. leprae is not closely related to any other mycobacterium, but that its relationship to $M$. tuberculosis is less distant than that to other mycobacterial species or to species of Nocardia and Corynebacterium. Numerous phenotypic characters, particularly immunological reactivity and the chemical nature of its lipids, underline the mycobacterial nature of $M$. leprae. The unusual peptidoglycan structure and the anomalously low G + C content (Imaeda et al., 1982; Clark-Curtiss et al., 1985 ) apparently contradict this. Further information on the relationships of $M$. leprae to other organisms seems needed.

We are grateful to Dr P. R. Wheeler and Mrs A. C. Lowe for some of the residues used to prepare walls, to Miss S. Lathwell for amino acid analyses and GLC of sugars and to Ross Maxwell for running the NMR experiments.

\section{REFERENCES}

Abou-Zeid, C., Volland, A., Michel, G. \& Cocito, C. (1982). Chemical composition of cell-wall polysaccharides from leprosy-derived corynebacteria. FEMS Microbiology Letters 15, 185-188.

Athwal, R. S., Deo, S. S. \& Imaeda, T. (1984). Deoxyribonucleic acid relatedness among Mycobacterium leprae, Mycobacterium lepraemurium, and selected bacteria by dot blot and spectrophotometric deoxyribonucleic acid hybridization assays. International Journal of Systematic Bacteriology 34, 371375.

Bricas, E., Ghuysen, J.-M. \& Dezelee, P. (1967). The cell wall peptidoglycan of Bacillus megaterium KM. 1. Studies on the stereochemistry of $\alpha, \alpha^{\prime}$-diaminopimelic acid. Biochemistry 6, 2598-2607.

Clark-Curtiss, J. E., Jacobs, W. R., Docherty, M. A., Ritchie, L. R. \& Curtiss, R. (1985). Molecular analysis of DNA and construction of genomic libraries of Mycobacterium leprae. Journal of Bacteriology 161, 1093-1102.

DARBRE, A. \& IsLAM, A. (1968). Gas-liquid chromatography of trifluoroacetylated amino acid methyl esters. Biochemical Journal 106, 923-925.

DAVID, H. L. \& RastogI, N. (1983). Partial characterization of the cell walls of Mycobacterium leprae. Current Microbiology 9, 269-274.

DAvidson, L. A. (1976). The surface structure of pathogenic mycobacteria. PhD Thesis, University of London.

Davidson, L. A., Draper, P. \& Minnikin, D. E. (1982). Studies on the mycolic acids from the walls of Mycobacterium microti. Journal of General Microbiology 128, 823-828.

DRAPER, P. (1971). The walls of Mycobacterium lepraemurium: chemistry and ultrastructure. Journal of General Microbiology 69, 313-324.

DRAPER, P. (1976). Cell walls of Mycobacterium leprae. International Journal of Leprosy 44, 95-98.

Dubois, M., Gilles, K. A., Hamilton, J. K., Rebers, P. A. \& SMITH, F. (1956). Colorimetric method for determination of sugars and related substances. Analytical Chemistry 28, 350-356.
FujIOKA, M., Koda, S. \& Morimoto, Y. (1985). Novel glycosidic linkage between arabinogalactan and peptidoglycan in the cell wall skeleton of Nocardia rubra AN-115. Journal of General Microbiology 131, 1323-1329.

HALPERN, B. (1977). Derivatives for chromatographic resolution of optically active compounds. In Handbook of Derivatives for Chromatography, pp. 457-499. Edited by K. Blau \& G. S. King. London: Heyden.

HAMmes, W., SChleifer, K. H. \& KandLER, O. (1973). Mode of action of glycine on the biosynthesis of peptidoglycan. Journal of Bacteriology 116, 1029-1053.

HOARE, D. S. \& WORK, E. (1957). The stereoisomers of $\alpha, \varepsilon$-diaminopimelic acid. 2. Their distribution in the bacterial order Actinomycetales and in certain Eubacteriales. Biochemical Journal 65, 441-447.

IMAEDA, T., Kirchieimer, W. F. \& BARKSDALE, L. (1982). DNA isolated from Mycobacterium leprae: genome size, base ratio, and homology with other related bacteria as determined by optical DNADNA reassociation. Journal of Bacteriology 150, 414417.

Kanetsuna, F. \& SAN Blas, G. (1970). Chemical analysis of a mycolic acid-arabinogalactan-mucopeptide complex of mycobacterial cell wall. Biochimica et biophysica acta 208, 434-443.

Kawamoto, I., OKa, T. \& Nara, T. (1981) Cell wall composition of Micromonospora olivasterospora, Micromonospora sagamiensis, and related organisms. Journal of Bacteriology 146, 527-534.

Kotani, S., Watanabe, Y., Shimono, T., Kinoshita, F., Narita, T., Kato, K., Stewart-Tull, D. E. S., Morisaki, I., Yokogawa, K. \& Kawata, S. (1975). Immunoadjuvant activities of peptidoglycan subunits from the cell walls of Staphylococcus aureus and Lactobacillus plantarum. Biken Journal 18, 93-103.

LeDerer, E. (1971). The mycobacterial cell wall. Pure and Applied Chemistry 25, 135-165.

LEDERER, E. (1975). Cell walls of mycobacteria and related organisms; chemistry and immunostimulant properties. Molecular and Cellular Biochemistry 7 , 87-104. 
Minnikin, D. E. (1982). Lipids: complex lipids, their chemistry, biosynthesis and roles. In The Biology of the Mycobacteria, vol. 1, pp. 95-184. Edited by C. Ratledge \& J. L. Stanford. London: Academic Press.

Minnikin, D. E., Minnikin, S. M., Parlett, J. H. \& GoODFELLOW, M. (1985). Mycolic acid patterns of some rapidly-growing species of mycobacterium. Zentralblatt für Bakteriologie, Parasitenkunde und Hygiene, series A 259, 446-460.

Misaki, A. \& YUKaWA, S. (1966). Studies on cell walls of mycobacteria. II. Constitution of polysaccharides from BCG cell walls. Journal of Biochemistry 59, 51 1520.

Misaki, A., Seto, N. \& AZuma, I. (1974). Structure and immunological properties of D-arabino-D-galactan isolated from cell walls of Mycobacterium species. Journal of Biochemistry 76, 15-27.

Nara, T., Kawamoto, I., Okachi, R. \& OKa, T. (1977). Source of antibiotics other than streptomyces. Japanese Journal of Antibiotics 30, S174-S189.

PARK, J. T. \& Johnson, M. J. (1949). A submicro determination of glucose. Journal of Biological Chemistry 181, 149-151.

Schleifer, K. H. \& Kandler, O. (1972). Peptidoglycan types of bacterial cell walls and their taxonomic implications. Bacteriological Reviews 36, 407-477.
Shepard, C. C., Draper, P., Rees, R. J. W. \& Lowe, C. (1980). Effect of purification steps on the immunogenicity of Mycobacterium leprae. British Journal of Experimental Pathology 61, 376-379.

STACKeBRANDT, E. \& SCHLEIFER, K.-H. (1984). Molecular systematics of actinomycetes and related organisms. In Biological, Biochemical, and Biomedical Aspects of Actinomycetes, pp. 485-504. Edited by L. Ortiz-Ortiz, L. F. Bojalil \& V. Yakoleff. Orlando, Florida: Academic Press.

Szaniszlo, P. J. \& Gooder, H. (1967). Cell wall composition in relation to the taxonomy of some Actinoplanaceae. Journal of Bacteriology 94, 20372047.

UCHIDA, K. \& AIDA, K. (1977). Acyl type of bacterial cell wall: its simple identification by colorimetric method. Journal of General and Applied Microbiology 23, 249-260.

World Health Organization (1980). UNDP/World Bank/WHO Special Programme for Research and Training in Tropical Diseases. Report of the Fifth Meeting of the Scientific Working Group on the Immunology of Leprosy (IMMLEP). TDR/IMMLEP-SWG(5)/80.3, Annex 4, p. 23. Geneva: World Health Organization. 